
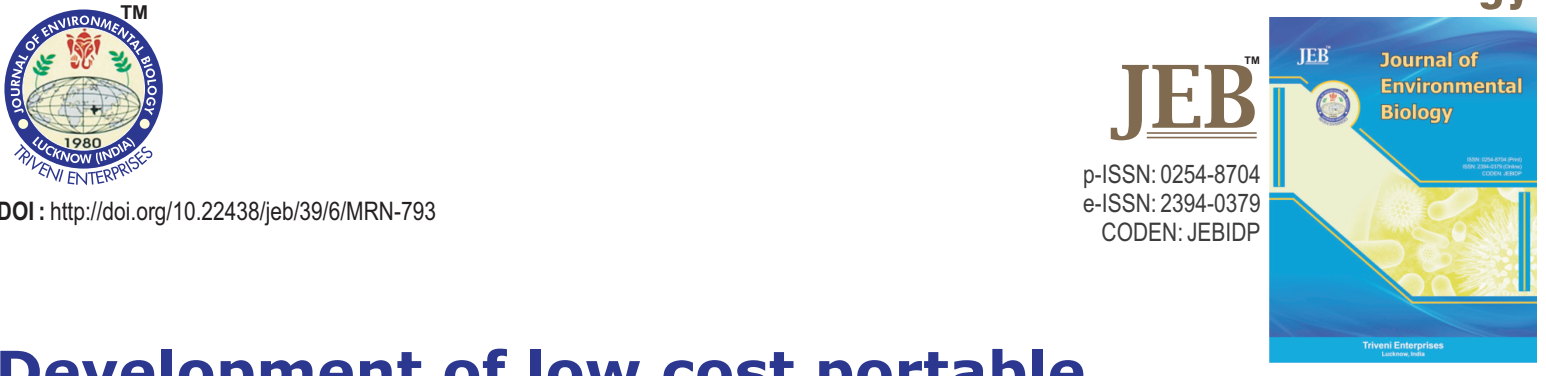

\title{
Development of low cost portable biomass fired dryer for cardamom drying in hilly areas
}

Authors Info

S. Mandal ${ }^{1 *}$, H.R. Tanna ${ }^{2}$, A. Nath ${ }^{3}$, R.K. Singh ${ }^{4}$ and A. Kumar

'ICAR-Central Institute of Agricultural Engineering, Nabibagh, Bhopal- 462 038, India

${ }^{2}$ College of Agricultural Engineering and Technology, Anand Agricultural University, Anand-389 001, India

${ }^{3}$ ICAR-IIFSR, Modipuram, Meerut-250 110, India

${ }^{4} \mathrm{AICRP}$ on Plasticulture, CIPHET, PAU campus, Ludhiana-141 004, India

${ }^{5}$ ICAR-Central Institute for Research on Goat, Makhdum-281 122, India

*Corresponding Author Email : smandal2604@gmail.com

Key words

Biomass

Cardamom

Dryer

Publication Info

Paper received : 24.11.2017

Revised received : 27.03 .2018

Re-revised received: 11.04 .2018 Accepted: 18.04 .2018

\begin{abstract}
Aim : The aim of the present study was to develop a low cost portable biomass fired dryer for cardamom (Amomum subulatum Roxburgh) drying in hilly areas.
\end{abstract}

Methodology : A low-cost and portable biomass fired dryer was designed and evaluated for its suitability for drying large cardamom. The dryer was made in two halves containing the drying trays in upper half and the biomass burner in lower half. The upper half and lower half weighed 22 and $16 \mathrm{~kg}$, respectively, making it light weight and portable.

Results : It was observed that large cardamom was dried from about $80 \%$ initial moisture to $10 \%$ final moisture content in $14 \mathrm{hrs}$ for $20 \mathrm{~kg}$ loading and $19 \mathrm{hrs}$ for $30 \mathrm{~kg}$ loading. It was also found that for drying of 20 and $30 \mathrm{~kg}$ fresh cardamom, 14 and $19.5 \mathrm{~kg}$ biomass was burnt and moisture driven away was $14.07 \mathrm{~kg}$ and $20.8 \mathrm{~kg}$, respectively. Thus, the average fuel requirement for drying of per $\mathrm{kg}$ large cardamom was 0.67 $\mathrm{kg}$. The cost of the dryer was found to be Rs. 8300 (USD 127.66) and cost of drying $100 \mathrm{~kg}$ cardamom was Rs. 245 (US \$ 3.81).

Interpretation : The developed cardamom dryer was found portable and low-cost. It consumed lesser fire wood than traditional bhatti system, required lesser drying time and delivered higher quality of dried products in terms of moisture content and colour values.

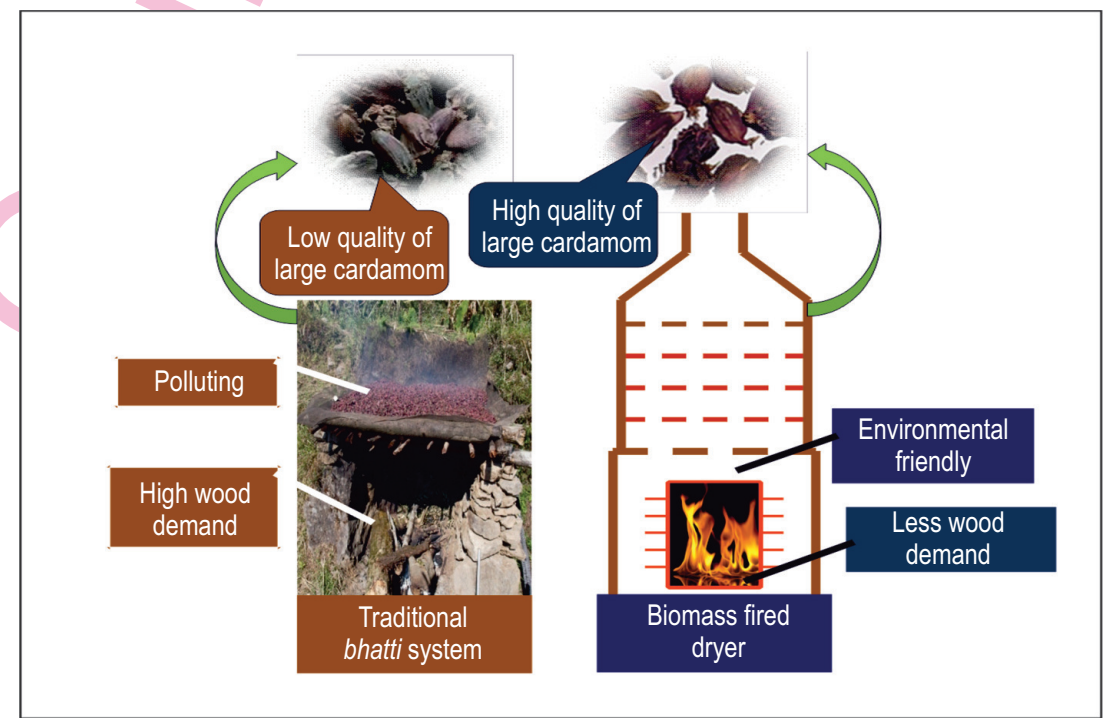




\section{Introduction}

Large cardamom (Amomum subulatum Roxburgh) is one of the major cash crops in India producing $53.3 \%$ of global production followed by Nepal $(33.3 \%)$ and Bhutan (13.3\%). In India, the state of Sikkim from North East produces $85 \%$ of total production in the country (Pathak, 2008). This crop is mostly grown in hilly region at an altitude of 1000 to $2000 \mathrm{~m}$ (Singh et al., 1989; Rao et al., 2001). For better aroma and storage quality, large cardamom is dried from an initial moisture content of $80 \%$ to less than $10 \%$ wet basis (w.b.) and this process is known as curing, which has to be done immediately after harvesting to avoid fungal infection (Mande et al., 1999; Ducourtieux et al., 2006). Farmers practice traditional method called Bhattifor curing which causes degradation in quality of the product fetching meagre remuneration (Chua and Chou, 2003). This process also produces huge amount of smoke degrading the quality of product and polluting the surrounding environment (Mandal et al., 2014). Attempts have been made in the past to study the Bhatti system and to improve its design or to replace by gasifier based curing chambers which worked well. With a more advance attempt, a trolley type tray dryer of $600 \mathrm{~kg}$ per batch capacity was designed, developed and evaluated. It was equipped with a heat exchanger based on diesel fuel. It could dry the product at controlled temperature giving high grade quality of the dried product (Sharma et al., 2009; Bhutia et al., 2017).

However, all these modified dryers are stationary, operated by diesel fuel or electricity and require high initial investment. Small farmers are not financially sound to afford the bigger units and access to electricity in the remote areas is scarce. They have to carry their harvested materials to the drying station which is cumbersome and time consuming. To avoid this hard work, they go for the traditional bhatti system of drying. Hence, to encourage the growers, this study was undertaken to replace the bhatti system with a modified drier. Therefore, objectives of this study were to develop a portable and low-cost biomass fired drier for drying of large cardamom using locally available biomass and to evaluate its performance in terms of drying time, temperature profile and dried product quality.

\section{Materials and Methods}

Development of portable dryer : The dryer was fabricated in two halves to make it portable so that it can be moved by two persons. The upper half consisted of drying cabinet, four drying trays and the hood (Fig. 1). Drying trays with aluminum wire mesh base were of $1.2 \mathrm{~m} \times 0.8 \mathrm{~m}$ size and spaced $150 \mathrm{~mm}$ apart. Thus, they provided total drying area of $3.84 \mathrm{~m}^{2}$. Three walls and the hood of the drying cabinet were closed by $0.35 \mathrm{~mm}$ galvanized iron (GI) sheet and insulated using $5 \mathrm{~mm}$ plywood board. Asquare shape opening of $75 \mathrm{~mm} \times 75 \mathrm{~mm}$ was provided at the top for escape of moist air. A damper was placed over the opening to reduce the speed of escaping hot air. Drying cabinet is accessible through two hinged doors provided in the front side of the dryer. Wooden sliding rollers were provided below the drying trays for easy loading, unloading and cleaning. The whole upper half weighed $22 \mathrm{~kg}$ which could be easily transported by two persons. The upper half was fitted above lower half and was air sealed by rubber strips.

Lower half consisted of a heating chamber which housed the biomass burner. The biomass burner can be accessed through a door at one side of the heating chamber. Concept of indirect heating was adopted so that product was not contaminated with flue gas. Fresh air was heated by the burner which flowed from outside through rectangular vents, provided at two sides at the bottom of the heating chamber. The opening area of vents could be adjusted by using rotating flaps. An opening was provided in the burner door in which a glass visor was fixed to inspect the biomass burning. An adjustable flap was fixed on one side of the burner to control the airflow for burning of biomass. To delay the movement of flue gas and to increase the heat transfer, a baffle was provided inside the burner as shown in Fig. 1. The burner walls were made of used vegetable oil containers $(0.25 \mathrm{~mm}$ tin sheet) and insulated with $15 \mathrm{~mm}$ thick glass wool. Aluminum sheet of $200 \mathrm{~mm} \times 40 \mathrm{~mm}$ size were riveted to each side of the burner surface at $25 \mathrm{~mm}$ spacing to increase heat transfer rate from burner to incoming fresh air. Weight of the lower half including burner was $16 \mathrm{~kg}$ making total weight of the dryer as $38 \mathrm{~kg}$.

Operation of the dryer : In operation, the burner surface and vertically attached aluminum sheets were heated by the heat generated from burning biomass inside the burner. The flowing ambient air was heated by hot surfaces of fins and moved upside picking moisture from each tray on its path. The moist hot air went out of the burner through the rectangular outlet provided at the top. Continuous flow of air was maintained by natural convection (Koppejan and Loo, 2012). The temperature inside heating chamber was controlled by controlling the air flow with rotating flaps.

After loading fresh materials to the trays, burner was loaded with $500 \mathrm{~g}$ biomass (having $<20 \%$ moisture) and a fire was started. A small fire was carefully maintained to keep the drying temperature as $65^{\circ} \mathrm{C}$ at the bottom of first tray. To achieve this, very small quantity of biomass was fed every time to the burner as suggested by Bena and Fuller (2002). When the temperature was abruptly high, the flaps of heating chamber were fully opened to allow more air inside the chamber to reduce the temperature. Biomass feeding was stopped when moisture content of cardamom reached $10 \%$. Remaining biomass and charcoal were taken out and weighed.

Properties of large cardamom : Dimensional properties of freshly harvested large cardamom such as length $(\mathrm{L})$, width $(\mathrm{W})$ and thickness $(T)$ were measured using a digital vernier caliper having $0.01 \mathrm{~mm}$ accuracy. The geometric mean diameter $(\mathrm{Dg})$ was calculated by the formula of Mohsenin (1978). Moisture content was determined by standard hot air oven method, keeping the cardamom for $48 \mathrm{hrs}$ at $65^{\circ} \mathrm{C}$ temperature (Gupta and Das, 1997). 
Drying of large cardamom : Freshly harvested large cardamoms were transported to ICAR RC NEH, Umiam, Meghalaya from ICAR Sikkim centre at Tadong, Gangtok and stored at $4^{\circ} \mathrm{C}$ temperature in sealed plastic bags. Before starting of drying experiment, large cardamoms were taken out and kept in ambient conditions for two hours to normalize the temperature. The dryer was tested for two capacities viz., 20 and $30 \mathrm{~kg}$. Each tray was loaded with $5 \mathrm{~kg}$ of cardamom while testing for $20 \mathrm{~kg}$ capacity and $7.5 \mathrm{~kg}$ for $30 \mathrm{~kg}$ capacity, respectively. Five temperature probes were installed over four trays inside heating chamber. Five small containers of $50 \mathrm{~mm} \times 50 \mathrm{~mm}$ size were placed on each tray- one at the center and four at each four corners. A representative sample of $100 \mathrm{~g}$ cardamom was put inside these containers. After every one hour, weight of these containers were noted to record moisture loss. Trays were not interchanged throughout the drying period, but lower most tray was removed once the cardamom reached the equilibrium moisture content. Overall thermal efficiency of the dryer was calculated as the ratio of heat required to evaporate the moisture from the cardamom capsules and heat supplied by burnt biomass (Yahya et al., 2017).

Quality evaluation of large cardamom : Quality evaluation of large cardamom was done based on the final moisture content and the change in visual colour after drying. Visual colour of large cardamom samples was determined before and after drying experiments using a tri-stimulus colorimeter which was calibrated using white and black standard ceramic tiles. The colour was expressed in terms of ' $L$ ' value [lightness, ranging from zero (black) to 100 (white)], 'a' value [ranging from +60 (red) to -60 (green)] and 'b' value [ranging from +60 (yellow) to -60 (blue)] which were measured using D-65 illuminant and $10^{\circ}$ observer. The total colour difference (TCD), a combination of $L$, $a$ and $b$ values, was used to characterize the overall change in colour after drying (Kaleemullah and Kailappan, 2006; Cubero et al., 2011; Saxena et al., 2012; Yemmireddy et al., 2013). There was non-uniformity in appearance on the fresh cardamom capsules. Therefore, colour values were taken only at the centre of the capsule surface where colour was uniform in almostall the capsules.

\section{Results and Discussion}

Average length, width and thickness of fresh large cardamom were found to be $22.29 \pm 1.30 \mathrm{~mm}, 17.93 \pm 0.86 \mathrm{~mm}$ and $14.66 \pm 0.66 \mathrm{~mm}$, respectively. The geometric mean diameter was calculated as $18.02 \pm 0.75 \mathrm{~mm}$. Fresh large cardamom capsules contained $78.71 \pm 0.92 \%$ initial moisture (w.b.). Large cardamom was dried from about $80 \%$ initial moisture to $10 \%$ final moisture content. Total drying time was found to be $14 \mathrm{hrs}$ for 20 $\mathrm{kg}$ loading and $19 \mathrm{hrs}$ for $30 \mathrm{~kg}$ (Fig. 2) which was much lesser than the traditional bhatti system where it took 25-40 hrs as reported by Mande et al. (1999). However, the dryer took more

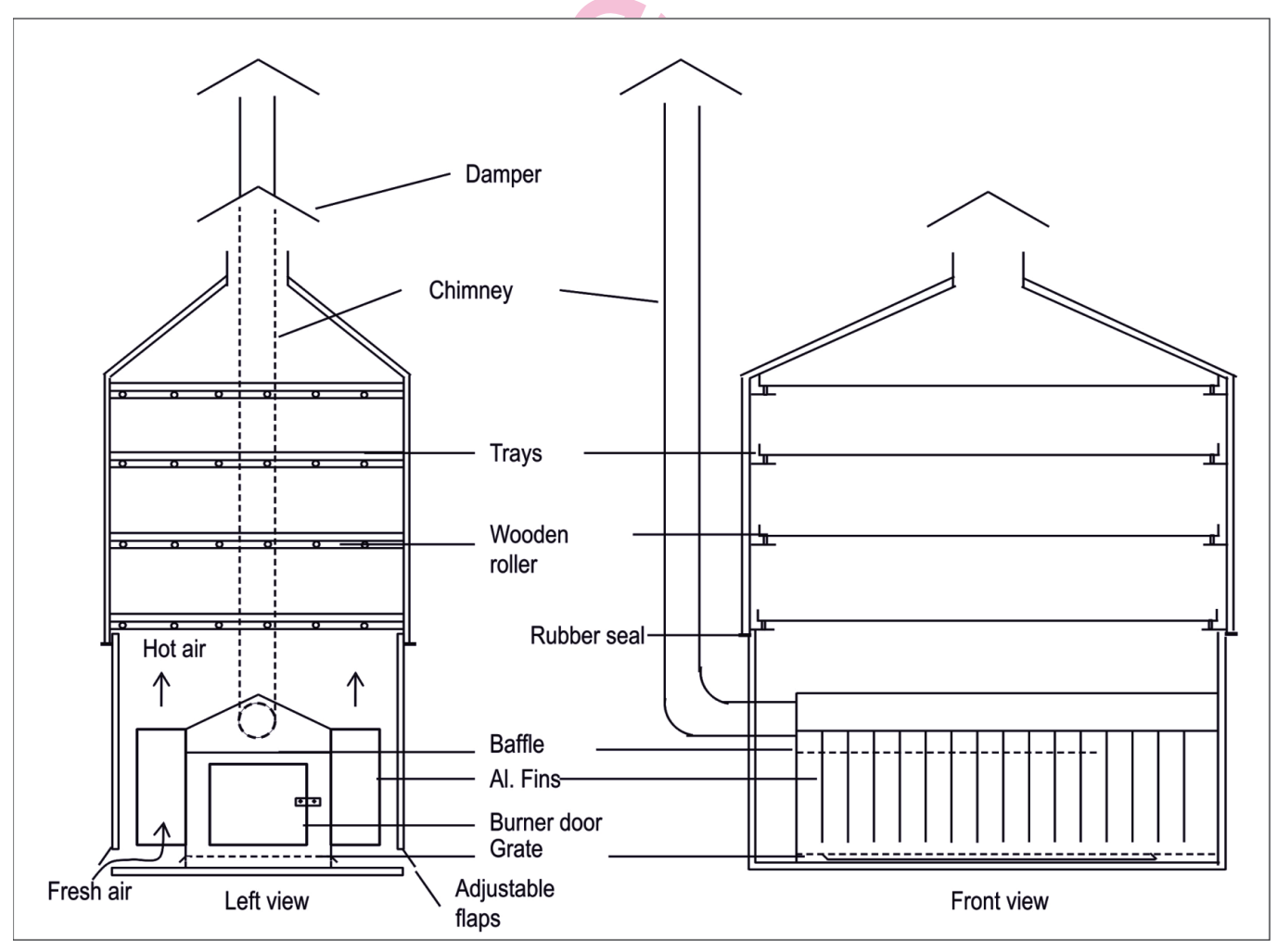

Fig. 1 : Low-cost portable large cardamom dryer. 

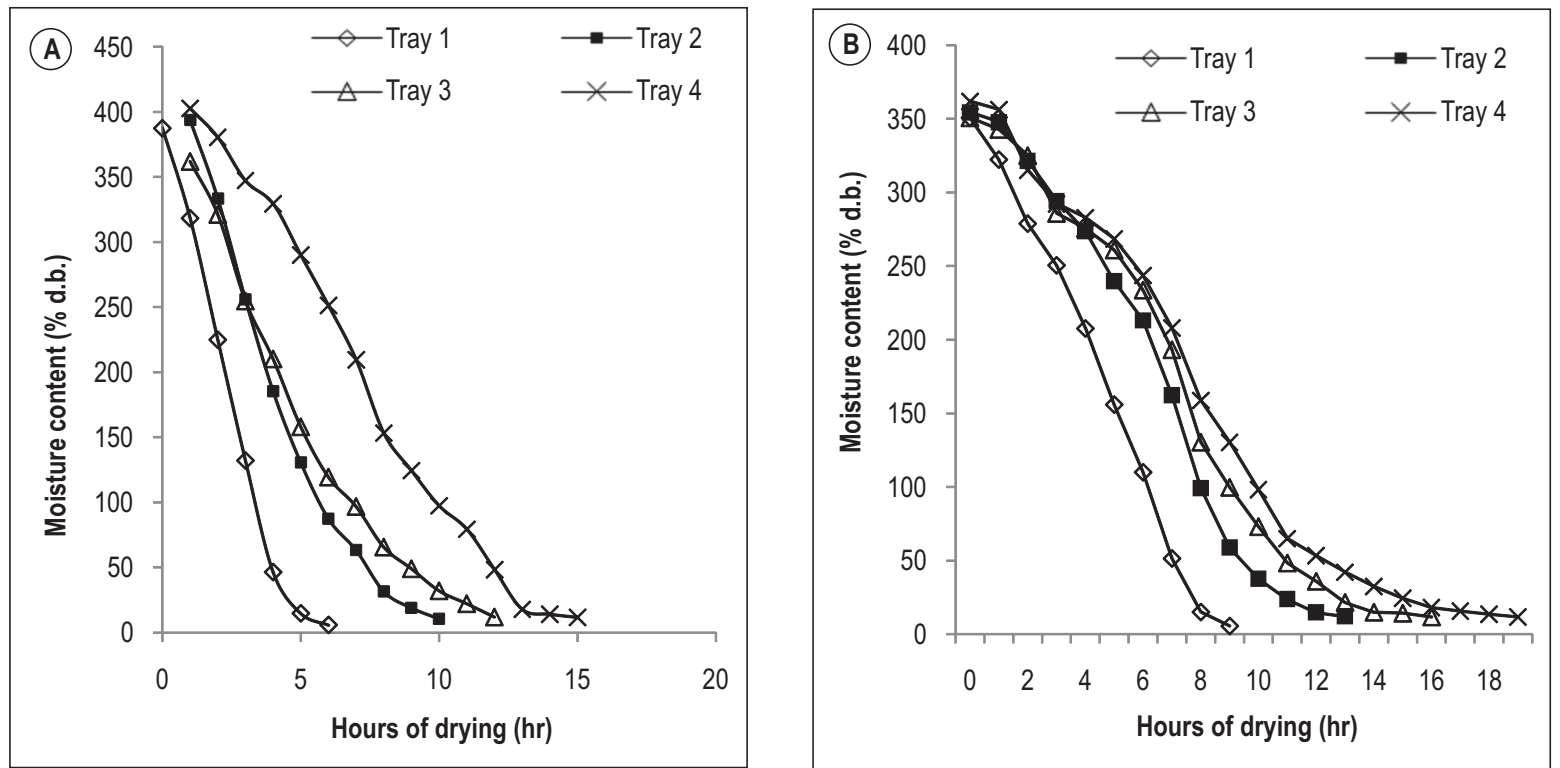

Fig. 2 : Moisture reduction curve of large cardamom at different tray levels: (A) $20 \mathrm{~kg}$ and (B) $30 \mathrm{~kg}$ loading.

time than the kiln dryer $(9.5-13.0 \mathrm{hrs})$ reported by Balakrishnan et al. (2011). Thickness of material on the trays was 15 and $21 \mathrm{~mm}$ for 20 and $30 \mathrm{~kg}$ loading, respectively. The higher bed thickness took more time for $30 \mathrm{~kg}$ loading. Similar findings were reported by Ilis and Demir (2018). Higher variations in drying conditions in different tray levels were observed. The bottom tray dried very fast in both the cases which took 6 and 9 hrs for 20 and $30 \mathrm{~kg}$ loading, respectively. The top most tray took 14 and $19 \mathrm{hrs}$ in the respective

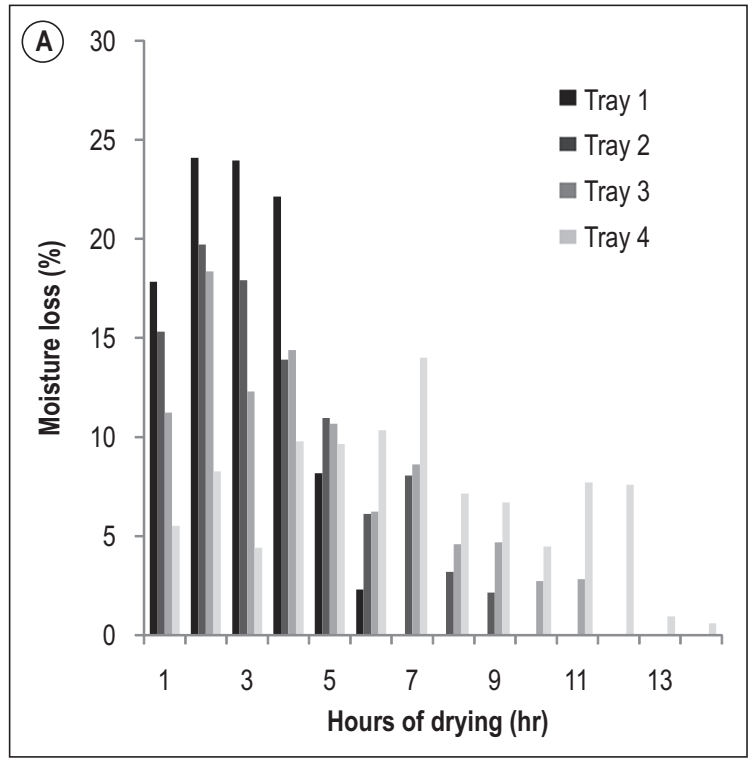

loading of 20 and $30 \mathrm{~kg}$. Similar results were reported by Bena and Fuller (2002) for natural convection solar-biomass hybrid dryer.

Moisture loss gradually decreased from bottom tray to top tray with time (Fig. 3). The cardamom of bottom tray lost $88 \%$ moisture within the first four hours and followed by second and third trays from bottom which lost 67 and $56 \%$ moisture, respectively in case of $20 \mathrm{~kg}$ loading. This condition was reached

Fig. 3 : Moisture loss pattern of large cardamom at different tray levels: (A) $20 \mathrm{~kg}$ and (B) $30 \mathrm{~kg}$ loading. 

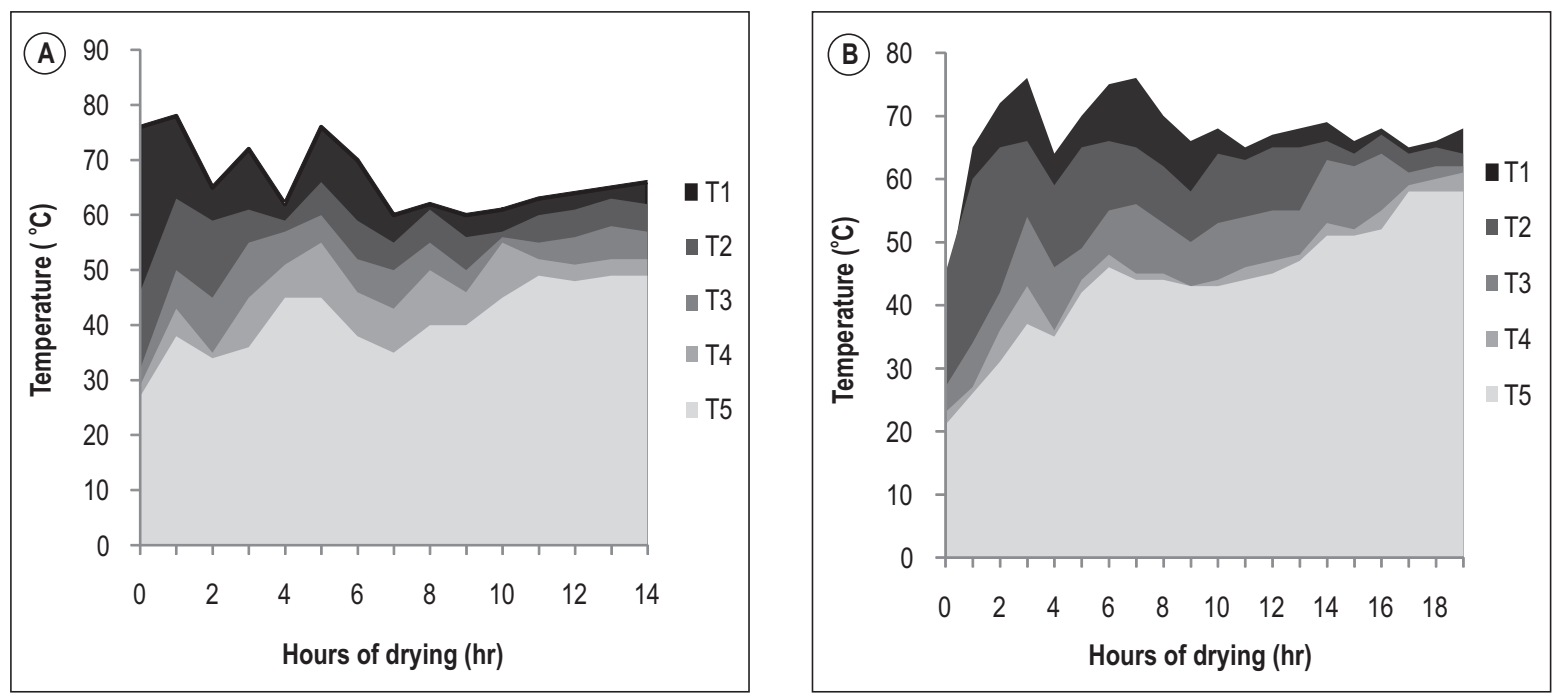

Fig. 4 : Temperature profile inside the dryer at different tray levels: (A) $20 \mathrm{~kg}$ and (B) $30 \mathrm{~kg}$ loading (T1 is the temperature below Tray 1 and $T 2$ to $T 5$ are the temperatures above Tray 1 to Tray 4 , respectively).

after eight hours for $30 \mathrm{~kg}$ loading. The moisture loss pattern of large cardamom dried in this dryer may not be similar to the electrical dryer because temperature was not constant throughout the time and varied considerably.

The temperature was recorded at heating chamber ( $\mathrm{T} 1$ ) and on top of each tray (T2 to T5). Maximum temperature in the heating chamber was recorded to be $76^{\circ} \mathrm{C}$ (Fig. 4) which was more than the recommended temperature for drying of biological materials i.e., $65^{\circ} \mathrm{C}$ as reported by Mukhopadhyay and Siebenmorgen (2017). Therefore, the efforts were made to reduce the temperature of heating chamber to save the materials of the bottom tray. This was done by opening the doors of heating chamber and allowing more air to enter which reduced the temperature. The average temperature of heating chamber was found to be $67^{\circ} \mathrm{C}$ which was close to the recommended temperature. Average temperature of the subsequent trays (T2 to T5) reduced by 7,9 and $6^{\circ} \mathrm{C}$, respectively, as the heated air moved slowly upward after picking the moisture and loosing enthalpy.

Cardamoms in all the trays had attained a final moisture content of $10 \%$ dry basis (d.b.). This value of moisture content is safe for long term storage of spices as reported by Jin et al. (2017). Quality of large cardamom is best judged by the colour value because pinkish products fetch the maximum remuneration in the market. On drying, pinkish colour of fresh cardamom fades and turns brownish or blackish which reduces the selling cost of the product significantly (Bhutia et al., 2017). After drying, considerable changes in Hunter colour coordinates, $L ; a ; b$ were observed. After drying of large cardamom, average 'L' colour value of dried products was observed as 33.78 where it was 37.25 for fresh cardamom (Table 1). It was lowered further to 30.56 for those which dried at close vicinity to the burner at the bottom tray.
There was more decrease in colour 'a' values which indicated decrease in red colour. The poor quality dried products registered colour 'a' value of 5.74 which was much lower than the fresh cardamom. Little change in 'b' colour value was observed in dried large cardamom. The brightness of dried large cardamom was highest in Tray 4 which was farthest from the burner. The change in colour 'a' was very high in cardamom of Tray 1 . Increase in TCD was in the range of 6.58 to 9.78 indicating change in visual colour. Similar kinds of colour degradation patterns were reported for jackfruit (Saxena et al., 2012) and kiwi fruit (Maskan, 2001) due to thermal treatment.

The cardamom of Tray 1 which was close to the burner dried faster due to high temperature and first exposure of incoming hot air with less humidity. High temperature caused higher TCD and higher proportion of poor quality product. The quality and proportion of good quality large cardamom increased in the trays with the distance from burner. Bena and Fuller (2002) experienced the same while drying pineapple slices using a hybrid dryer in burner mode at night. There was not much difference in quality of dried large cardamom at two loading rates. For drying of 20 and $30 \mathrm{~kg}$ fresh cardamom, 14 and $19.5 \mathrm{~kg}$

Table 1: Hunter colour values of fresh and dried large cardamom

\begin{tabular}{lllllll}
\hline $\begin{array}{l}\text { Colour } \\
\text { values }\end{array}$ & Fresh & Tray 1 & Tray 2 & Tray 3 & Tray 4 & $\begin{array}{l}\text { Poor } \\
\text { quality }\end{array}$ \\
\hline $\mathrm{L}$ & 37.25 & 32.68 & 33.30 & 33.59 & 35.58 & 30.56 \\
$\mathrm{a}$ & 18.72 & 10.49 & 12.01 & 12.11 & 12.40 & 5.74 \\
$\mathrm{~b}$ & 6.79 & 4.14 & 6.59 & 7.21 & 7.57 & 5.31 \\
$\mathrm{TCD}$ & - & 9.78 & 7.79 & 7.56 & 6.58 & 14.67 \\
\% poor & - & 14.56 & 5.25 & 5.21 & 3.15 & - \\
\hline
\end{tabular}


biomass was burnt and moisture driven away was $14.07 \mathrm{~kg}$ and $20.8 \mathrm{~kg}$, respectively. Thus, average fuel requirement for drying of per kg large cardamom was $0.67 \mathrm{~kg}$, which was much lower than traditional methods which required $2.5 \mathrm{~kg}$ wood per $\mathrm{kg}$ of large cardamom (Rao et al., 2001). Considering the calorific value of biomass as $14 \mathrm{MJ} \mathrm{kg}^{-1}$, thermal efficiency of the dryer was found to be 18.28 and $19.39 \%$ for 20 and $30 \mathrm{~kg}$ loading, respectively. It indicated that higher loading reduced the fuel requirement for the dryer. When time is a constraint, with low loading, faster drying can be achieved. Similar findings were reported by Thanompongchar et al. (2017) in drying of glutinous rice crackers. The fins provided on two sides of the burner increased the heat exchange between air and the burner surface which increased the overall dryer efficiency.

The manufacturing cost of the dryer was calculated as Rs. 8300 (USD \$ 127.66). The life expectancy of the dryer was assumed to be four years. If the dryer was used only for drying of large cardamom, the dryer will be used for 30-45 days every year which is the harvesting period of large cardamom reported by Sharma et al. (2000). So, 30 batches of large cardamom will be dried using the dryer which would dry $900 \mathrm{~kg}$ of large cardamom and consume $585 \mathrm{~kg}$ wood costing Rs. 638 to 1064 (USD 9.82 to 16.37). Thus, drying cost per $100 \mathrm{~kg}$ of large cardamom will be only Rs. 245 (USD 3.81). In an electric dryer of the same capacity, drying cost was calculated to be Rs. 303 (USD 4.66) per $100 \mathrm{~kg}$. If the labour cost of transportation of raw large cardamom is considered in case of electric dryer, the total cost will be many folds higher than the dryer under study.

The biomass fired dryer developed for drying of large cardamom was found portable and low-cost. Drying of large cardamom can be achieved within shorter time period with low fuel consumption. Quality of dried products in terms of moisture content and colour values was found satisfactory.

\section{Acknowledgments}

The authors acknowledge the financial assistance provided by ICAR Research Complex for NEH Region, Umiam, Meghalaya, India and Joint Director, Regional Centre of ICAR RC $\mathrm{NEH}$, Tadong, Sikkim, India for supplying fresh large cardamom.

\section{References}

Balakrishnan, M., G.S.V. Raghavan, V.V. Sreenarayanan and R. Viswanathan: Batch drying kinetics of cardamom in a twodimensional spouted bed. Drying Technol., 29, 1283-1290 (2011).

Bena, B. and R.J. Fuller: Natural convection solar dryer with biomass back-up heater. SolarEnergy., 72, 75-83 (2002).

Bhutia, K. C., O. Bhutia, R. Chatterjee and A. Pariari: Post harvest processing and marketing of large cardamom in India. J. Crop Weed, 13, 212-218 (2017).

Chua, K. J. and S.K. Chou: Low-cost drying methods for developing countries. Trends Food Sci. Technol., 14, 519-528 (2003).

Cubero, S., N. Aleixos, E. Moltó, J. Gómez-Sanchis and J. Blasco: Advances in machine vision applications for automatic inspection and quality evaluation of fruits and vegetables. Food Bioprocess. Tech., 4, 487-504 (2011).

Ducourtieux, O., P. Visonnavong and J. Rossard: Introducing cash crops in shifting cultivation regions-the experience with cardamom in Laos. Agroforest. Syst., 66, 65-76 (2006).

Gupta, R.K. and S.K. Das: Physical properties of sunflower seeds. J. Agr. Eng. Res., 66, 1-8 (1997).

Ilis, G. G. and H. Demir: Influence of bed thickness and particle size on performance of microwave regenerated adsorption heat pump. Int. J. Heat Mass Transfer., 123, 16-24 (2018).

Jin, W., A. S. Mujumdar, M. Zhang and W. Shi: Novel drying techniques for spices and herbs: Areview. Food Eng. Rev., 1-12 (2017).

Kaleemullah, S. and R. Kailappan: Modelling of thin-layer drying kinetics of red chillies. J. Food Eng., 76, 531-537 (2006).

Koppejan, J. and S. V. Loo: The handbook of biomass combustion and co-firing. Routledge (2012)

Mandal, S., Arvind Kumar, R. K. Singh, S. V. Ngachan and K. Kundu: Drying, burning and emission characteristics of beehive charcoal briquettes: An alternative household fuel of Eastern Himalayan Region. J. Environ. Biol., 35, 543-548 (2014).

Mande, S., A. Kumar and V. V. N. Kishore. A study of large-cardamom curing chambers in Sikkim. Biomass Bioenerg., 16, 463-473 (1999).

Maskan, M.: Kinetics of colour change of kiwifruits during hot air and microwave drying. J. Food Eng., 48, 169-175 (2001).

Mohsenin, N.N.: Physical Properties of Plant and Animal Materials. Gordon and Breach Science Publishers, New York (1978).

Mukhopadhyay, S. and T.J. Siebenmorgen: Effect of airflow rate on drying air and moisture content profiles inside a cross-flow drying column. Drying Tech., 36, 1326-1341 (2018).

Pathak, A.: Cultivation of large cardamom in Sikkim. Ishani, 2, (2008).

Rao, V. G., S. Mande and V. V. N. Kishore: Study of drying characteristics of large-cardamom. Biomass Bioenerg., 20, 37-43 (2001).

Saxena, A., T. Maity, P. S. Raju and A. S. Bawa: Degradation kinetics of colour and total carotenoids in jackfruit (Artocarpus heterophyllus) bulb slices during hot air drying. Food Bioprocess Tech., 5, 672679 (2012).

Sharma, E., R. Sharma, K. K. Singh and G. Sharma: A boon for mountain populations: Large cardamom farming in the Sikkim Himalaya. Mt. Res. Dev., 20, 108-111 (2000).

Sharma, G., R. Sharma and E. Sharma: Traditional knowledge systems in large cardamom farming: Biophysical and management diversity in Indian mountainous regions. Indian J. Tradit. Know., 8 , 17-22 (2009).

Singh, K. A., R. N. Rai and D. T. Bhutia: Large cardamom (Amomum subulatum Roxb.) plantation-An age old agroforestry system in Eastern Himalayas. Agroforest. Syst., 9, 241-257 (1989).

Thanompongchart, P., P. Pintana, K. Phimphilai and N. Tippayawong: Utilization of biomass energy in drying of glutinous rice crackers. Energy Procedia, 138, 331-336 (2017).

Yahya, M., A. Fudholi and K. Sopian: Energy and exergy analyses of solar-assisted fluidized bed drying integrated with biomass furnace. Renew. Energy, 105, $22-29$ (2017).

Yemmireddy, V. K., M. S. Chinnan, W. L. Kerr and Y. Hung: Effect of drying method on drying time and physico-chemical properties of dried rabbiteye blueberries. LWT-Food Sci. Technol., 50, 739-745 (2013). 